\title{
Pengaruh Marketing Mix (4P) terhadap Loyalitas Konsumen pada Mini market Indomaret dan Alfamart di Kota Pematangsiantar
}

\section{The Influence of Marketing Mix (4P) on Consumer Loyalty on Indomaret and Alfamart Mini market in Pematangsiantar City}

\author{
Dedi Suhendro1)* \\ 1) AMIK Tunas Bangsa Pematangsiantar, Sumatera Utara-Indonesia \\ *Corresponding Author : e-mail: dedi.su@amiktunasbangsa.ac.id
}

\begin{abstract}
Abstrak
Tujuan penelitian untuk mengetahui pengaruh variabel independent baik secara simultan dan parsial terhadap variabel dependent. Populasi penelitian penduduk Pematangsiantar jumlah penduduk mencapai 247.411 jiwa. Dari rumus Slovin maka sampel yang digunakan penelitian ini adalah purposive sampling yang diseleksi dengan syarat dan kriteria untuk dijadikan sampel. Sedangkan seleksi yang tidak memenuhi syarat dan kriteria tidak dijadikan sampel. Sampel penelitian 100 orang. Data penelitian diolah menggunakan SPSS. Hasil hipotesis membuktikan bahwa variabel independent Marketing Mix (Produk Lokasi, Promosi dan Harga) tersebut secara simultan tidak memiliki pengaruh signifikansi terhadap variabel dependent (Loyalitas Konsumen) pada Mini market Indomaret dan Alfamart di Kota Pematangsiantar. Secara parsial produk tidak memiliki pengaruh terhadap Loyalitas konsumen. Lokasi tidak memiliki pengaruh terhadap Loyalitas konsumen. Promosi tidak memiliki pengaruh terhadap Loyalitas konsumen dan Harga tidak memilikipengaruh terhadap Loyalitas konsumen pada mini market Indomaret dan Alfamart di Kota Pematangsiantar.
\end{abstract}

Kata kunci: Marketing Mix, Loyalitas Konsumen, Mini market

\begin{abstract}
This study aims to determine the effect of independent variables both simultaneously and partially on the dependentt variable. The research population of the population of Pematangsiantar has a population of 247,411 people. From the Slovin formula, the sample used in this study was purposive sampling selected with terms and criteria to be sampled. Whereas the selection that does not meet the requirements and criteria is not sampled. The research sample was 100 people. Research data was processed using SPSS. The hypothesis results prove that the independent variables of Marketing Mix (Product Location, Promotion and Price) simultaneously have no significant effect on the dependentt variable (Consumer Loyalty) on the Indomaret and Alfamart Mini market in Pematangsiantar City. While partially the product does not affect consumer loyalty. Location does not affect consumer loyalty. Promotion does not affect consumer loyalty and price does not affect consumer loyalty at the Indomaret and Alfamart mini markets in Pematangsiantar City.
\end{abstract}

Keywords: Marketing Mix, Consumer Loyalty, Mini market

How to Cite: Dedi Suhendro (2019). Pengaruh Marketing Mix (4P) terhadap Loyalitas Konsumen pada Mini market Indomaret dan Alfamart di Kota Pematangsiantar . Jurnal Konsep Bisnis dan Manajemen. 4 (1): 206-220 


\section{PENDAHULUAN}

Penduduk Indonesia baik yang bermukim di perkotaan maupun pedesaan kini dimanjakan dengan adanya fasilitas perbelanjaan, bahkan letak perbelanjaan saling berdekatan. Situasi seperti ini sangat menguntungkan bagi penduduk karena banyak pilihan terhadap mini market yang dikunjungi. Berkembangnya bisnis ritel bukan hanya di pusat kota, melainkan sudah berkembang sampai kecamatan dan pedesaan. Bisnis ritel yang terkenal di Indonesia sekarang ini yaitu Indomaret dan Alfamart. Menjamurnya bisnis ritel ini menumbuhkan minat belanja penduduk karena tersedianya produk sehari-hari dengan layanan 24 jam, tempat lebih bersih, lebih nyaman, harga tertera pada produk, pengambilan barang dilakukan sendiri oleh konsumen, layanan yang ramah, diskon, dan promo barang sehingga kehadiran mini market Indomaret dan Alfamart sangat memberikan apresiasi yang memuaskan bagi penduduk Indonesia (Masyhuri \& Utomo, 2017) .Jumlah gerai dan ritel Indomaret dan Alfamart yang tersebar sampai tahun 2018 untuk kotamadya Pematangsiantar menurut data https://siantarkota.bps.go.id ada dalam tabel berikut:
Tabel 1. Jumlah gerai Indomaret dan Alfamart wilayah Pematangsiantar

\begin{tabular}{|ccccc|}
\hline \multirow{2}{*}{ No } & \multirow{2}{*}{ Gerai } & \multicolumn{2}{c}{ Jumlah Gerai } & Total \\
\cline { 3 - 4 } & & Kotamadya & Kabupaten & Gerai \\
\hline 1 & Indomaret & 25 & 23 & 48 \\
\hline 2 & Alfamart & 29 & 16 & 45 \\
\hline
\end{tabular}

Sumber: (BPS Pematangsiantar 2018)

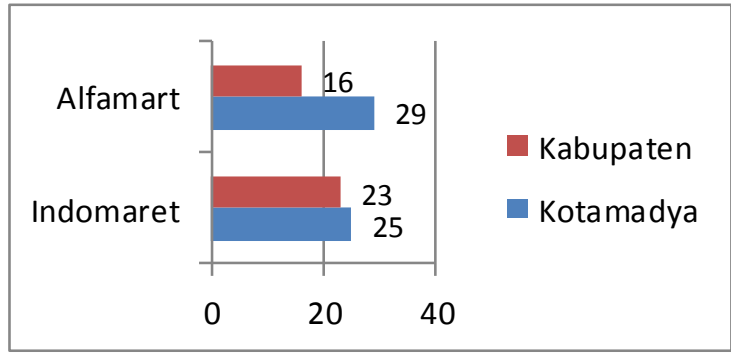

Gambar 1: Grafik gerai Indomaret dan Alfamart wilayah Pematangsiantar

Sampai tahun 2018 Indomaret memiliki gerai di kotamadya Pematangsiantar sebanyak 25 gerai dan di kabupaten sebanyak 23 gerai sehingga total gerai Indomaret mencapai 48 gerai dengan motto "mudah dan hemat". Sedangkan untuk Alfamart sendiri menurut data yang diperoleh sampai tahun 2018 memiliki gerai di kotamadya Pematangsiantar sebanyak 29 gerai dan di kabupaten sebanyak 16 gerai dengan motto "Belanja puas, harga pas" (20032015), "Belanja hemat, ya di Alfamart (2015- sekarang). Lokasi gerai Indomaret dan Alfamart mudah untuk dijangkau penduduk sehingga sangat strategis keberadaannya misalnya di daerah pemukiman, apartemen, wilayah perkantoran, kawasan niaga, daerah pariwisata dan lokasi lainnya. Tingkat 
belanja yang semakin tinggi dari para konsumen karena semakin banyak penjualan secara Online sehingga memberikan cambuk bagi usaha ritel untuk melakukan banyak inovasi-inovasi baru dalam menjalankan bisnis nya agar tetap bisa bertahan menghadapi persaingan global (Putra \& Giri, 2013).

Kota Pematangsiantar memiliki penduduk 247.411 jiwa berdasarkan kelompok umur dan jenis kelamin.
Tabel 2. Jumlah penduduk kotaPematangsiantar berdasarkan kelompok usia dan jenis kelamin

\begin{tabular}{|ccccc|}
\hline No & Usia & Pria & Wanita & Jumlah \\
\hline 1 & $0-4$ & 11.668 & 11.400 & 23.068 \\
\hline 2 & $5-9$ & 11.945 & 11.553 & 23.498 \\
\hline 3 & $10-14$ & 11.567 & 11.303 & 22.870 \\
\hline 4 & $15-19$ & 13.057 & 13.246 & 26.303 \\
\hline 5 & $20-24$ & 10.082 & 11.157 & 21.239 \\
\hline 6 & $25-29$ & 8.977 & 8.891 & 17.868 \\
\hline 7 & $30-34$ & 8.450 & 8.643 & 17.093 \\
\hline 8 & $35-39$ & 8.281 & 8.661 & 16.942 \\
\hline 9 & $40-44$ & 8.115 & 8.809 & 16.924 \\
\hline 10 & $45-49$ & 7.497 & 7.988 & 15.485 \\
\hline 11 & $50-54$ & 6.550 & 7.345 & 13.895 \\
\hline 12 & $55-59$ & 5.343 & 5.923 & 11.266 \\
\hline 13 & $60-64$ & 3.994 & 4.330 & 8.324 \\
\hline 14 & $65-69$ & 2.333 & 2.958 & 5.291 \\
\hline 15 & $70+$ & 2.738 & 4.607 & 7.345 \\
\hline Jumlah & 120.597 & 126.814 & 247.411 \\
\hline
\end{tabular}

Sumber: (BPS Pematangsiantar, 2018)

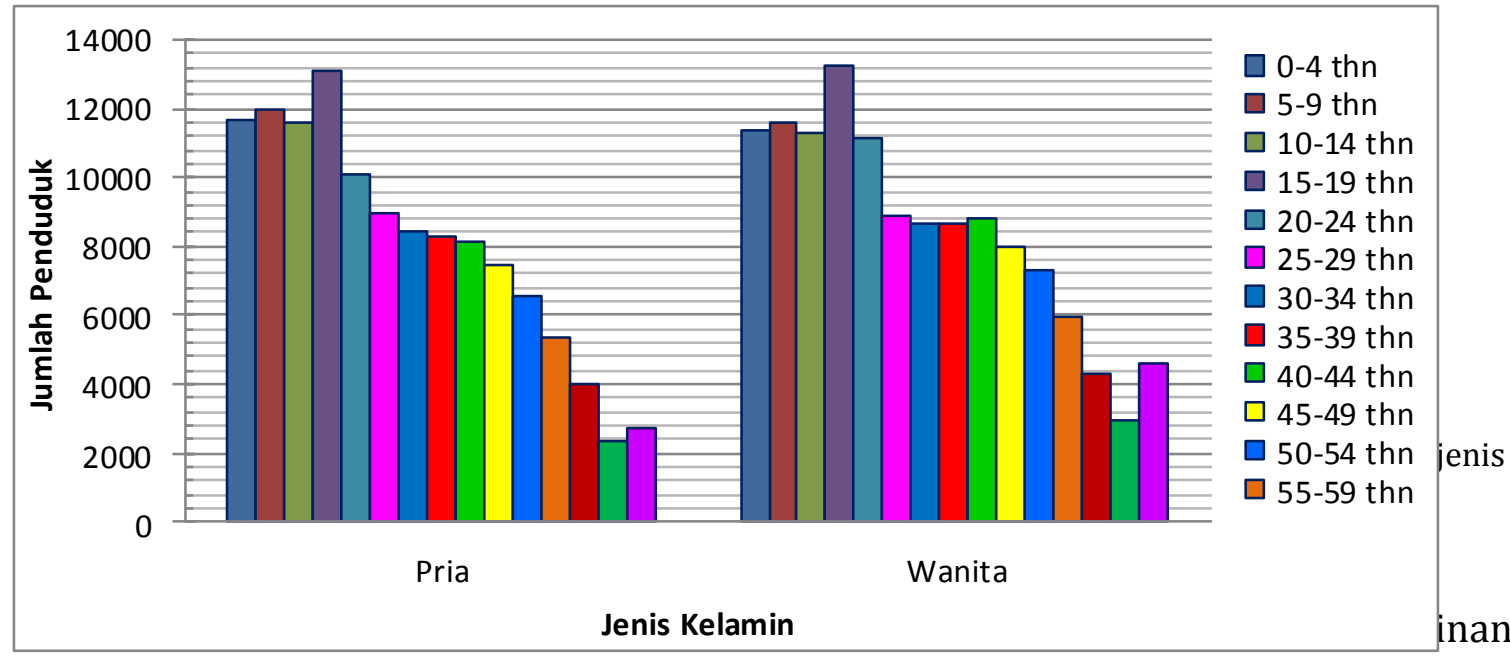

perbelanjaan gerai Indomaret dan konsumen untuk tetap dipertahankan Alfamart di Pematangsiantar akan (Rizka Nuri Puspita, 2012). Perusahaan semakin ketat pula persaingan sehingga ritel terus berevolusi seiring masing-masing perusahaan gencar untuk perkembangan terhadap perubahan, gaya mengadakan lebih serius pada dan daya beli konsumen. Suatu proses pemasaran, promosi serta pemberian adanya tuntutan dalam hal menciptakan diskon untuk menjaring konsumen agar segmen yang baru. Convenience store tetap loyal karena loyalitas sangat dulunya toko grocery hanya untuk pria 
sekarang tempat hang out pria dan wanita. Mini market melebar kearah yang lebih premium sedangkan hipermarket menjadi mid size, yang basic kini melangkah ke arah lifestyle. Menandakan perusahaan ritel bermetamorfosa dan berjuang agar tetap bertahan hidup berkembang untuk masa depan (Putra \& Giri, 2013). Aprindo memproyeksikan pertumbuhan gerai modern semakin meningkat. Terkait persaingan ritel berdasarkan hasil survei bahwa, pasar modern baik Indomaret dan Alfamart bersaing dengan ketat mernperebutkan pasar nasional (T.Teviana \& Eva Riyanti, 2015).

PT Indomarco Prismatama (Indomaret) dan PT Sumber Alfaria Trijaya Tbk, (Alfamart) merupakan bisnis ritel berupa mini market penjualan eceran yang menjual bahan pokok dan keperluan harian. Dua mini market terbesar saat ini yang memiliki daya saing ketat. Mini market pertama di Indonesia adalah Indomaret mulai dibentuk dari tahun 1988 (Muryuniarsih, Annisa Rahman, 2014). Data dari (Indomaret, 2018) hingga pebruari 2018 bahwa Indomaret memiliki 15.456 gerai, terdiri dari $60 \%$ milik sendiri dan $40 \%$ milik masyarakat. Semua tersebar di Jawa, Madura, Sumatera, Kalimantan dan Sulawesi. Sedangkan Alfamart memulai usaha komersilnya pada tahun 1989 khusus penjualan rokok. Mulai 2002 Alfamart berkembang dalam bisnis penjualan eceran kepada konsumen sama halnya seperti Indomaret. Data (Kompas, 2018) bahwa jumlah Alfamart sampai tahun 2018 mencapai 14.277 gerai di Indonesia

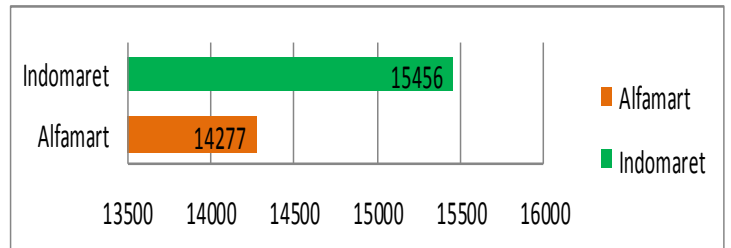

Gambar 3: Grafik jumlah gerai Indomaret dan Alfamart di Indonesia

Tujuan utama perusahaan dalam pemasaran adalah memaksimalkan penjualan, keutungan, pengembalian investasi dan menekan biaya (Masyhuri \& Utomo, 2017). Oleh karena itu penulis tertarik untuk mengangkat judul mengenai pengaruh marketing mix (produk, lokasi, promosi dan harga) terhadap loyalitas konsumen pada mini market Indomaret dan Alfamart di kota Pematangsiantar sehingga penulis memaparkan model persaingan dalam bidang bisnis antara mini market Indomaret dan Alfamart di kota Pematangsiantar sehingga dapat digunakan sebagai analisa, evaluasi dan manfaat bagi pebisnis.

Beberapa faktor dalam Marketing Mix diantaranya: produk (product), lokasi 
(place), harga (price) dan promosi (promotion):

\section{Produk (Product)}

Produk merupakan penawaran barang kepada konsumen agar memperoleh perhatian untuk dibeli, dikonsumsi, dan digunakan yang akhirnya dapat memenuhi kebutuhan (Marendra, 2018).

\section{Lokasi (place)}

Lokasi merupakan tempat atau beradanya sesuatu berhubungan dengan bagaimana mendistribusikan bisnisnya atau letak markas dari produsen beroperasi sehingga dapat menyalurkannya kepada konsumen (Marendra, 2018).

\section{Promosi (Promotion)}

Promosi adalah suatu kegiatan yang memperkenalkan produk, toko atau apapun yang tadinya orang tidak mengenal menjadi mengenal sehingga membujuk orang lain untuk membelinya melalui media promosi yang sangat menarik (Mustikawati dan Dody Prihatin Setia Budi 2012).

\section{Harga (Price)}

Harga adalah suatu unsur bertujuan untuk memberitahukan kepada konsumen tentang nilai produk dan mereknya yang dinyatakan dengan uang (Guruh Taufan Hariyadi, 2016).

\section{Loyalitas}

Loyalitas didefenisikan sebagai kesetiaan pelanggn atau konsumen dari brang, jasa dan tempat sehingga menjadi kepuasan konsumen dalam menggunakan fasilitas, layanan dari perusahaan (Danny dan Chandra 2001). Secara singkat Loyalitas konsumen merupakan kepercayaan dan kesetiaan dari pelanggn dan para konsumen dari jasa, merek, toko, tempat dan sebgainya, dalam pembelian ulang yang konsisten yang tidak terbentuk dalam waktu singkat, tetapi melalui hasil pengalaman sendiri dari pembelian yang konsisten sepanjang waktu (Fahmi dan Yuniati 2013).

\section{METODE PENELITIAN}

\section{Populasi dan sampel}

Penleitian ini memiliki populasi mencapai 247.411 jiwa penduduk kota Pematangsiantar yang bersumber dari (BPS Kota Pematangsiantar, 2017). Sementara penelitian ini menggunakan rumus Slovin:

$n=\frac{N}{1+N \cdot e^{2}}=\frac{247411}{1+247411 \cdot(10 \%)^{2}}=100$

Dimana:

$n=$ jumlah sampel

$\mathrm{N}=$ jumlah populasi

$e^{2} \quad=$ Tingkat kesalahan (10\%)

Dengan melihat rumus Slovin tersebut, dimana jumlah sampel (n) dari jumlah populasi 247.411 jiwa penduduk Pematangsiantar, tingkat kesalahan 10\% 
adalah mencapai 100 orang berdasarkan syarat dan kriteria yang ditentukan.

Purposive sampling digunakan untuk sampel penelitian ini adalah yang merupakan seleksi dengan syarat dan kriteria untuk dijadikan sampel. Sedangkan seleksi yang tidak memenuhi syarat dan kriteria tidak dapat dijadikan sampel dalam penelitian ini. Syarat dan kriteria menentukan sampel dalam penelitian ini adalah:

a) Sampel merupakan konsumen yang sering berbelanja di Alfamart dan
Indomaret yang bertempat tinggal di KotaPematangsiantar.

b) Sampel dari keluarga yang berbedabeda karena setiap sampel mewakili masing-masing keluarga.

c) Sampel tidak dibedakan dari pendidikan, usia dan jenkel untuk mendapatkan penelitian yang lebih variatif. Adapun kerangka konsep penelitian sebagai berikut:

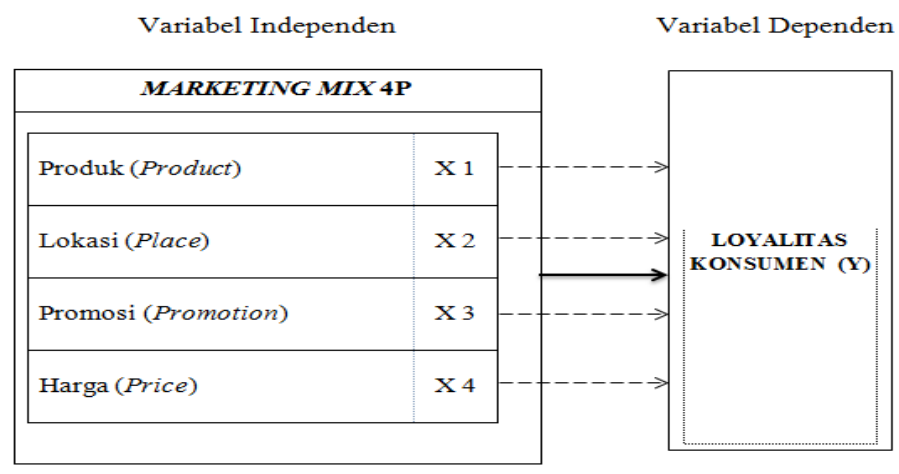

Gambar 5: Kerangka Konsep Penelitian

\section{Instrumen penelitian}

Pengukuran variabel digunakan

skala likert dengan sebagai berikut:

Para responden diminta untuk menyatakan setuju atau tidak setuju atas dasar pendapat dan persepsi masingmasing. Dengan kriteria Sangat Setuju (SS) penilaian 5, Setuju (S) penilaian 4, Tidak Berpendapat (TB) penilaian 3, Tidak Setuju (TS) penilaian 2, dan Sangat Tidak Setuju (STS) penilaian 1.

\section{HASIL DAN PEMBAHASAN}

Uji Asumsi Klasik

Untuk mengetahui apakah data penelitian dapat dianalisis menggunakan persamaan regresi linear berganda (Fuad, Arifin dan Yulianto 2013). Penelitian ini menggunakan uji asumsi klasik (uji normalitas, uji heteroskedastisitas dan uji multikolinearitas) agar hasil dan estimasi dapat dipercaya dan tidak bias. 
Uji Normalitas

Untuk menguji normalitas, penelitian menggunakan uji kolmogorov-smirnov. Uji normalitas. Distribusi data secara normal bila nilai signifikan $>0,05$, disrtibusi data tidak normal bila signifikan $<0,05$ berarti.

Tabel 3. Uji Normalitas

One-Sample Kolmogorov-Smirnov Test

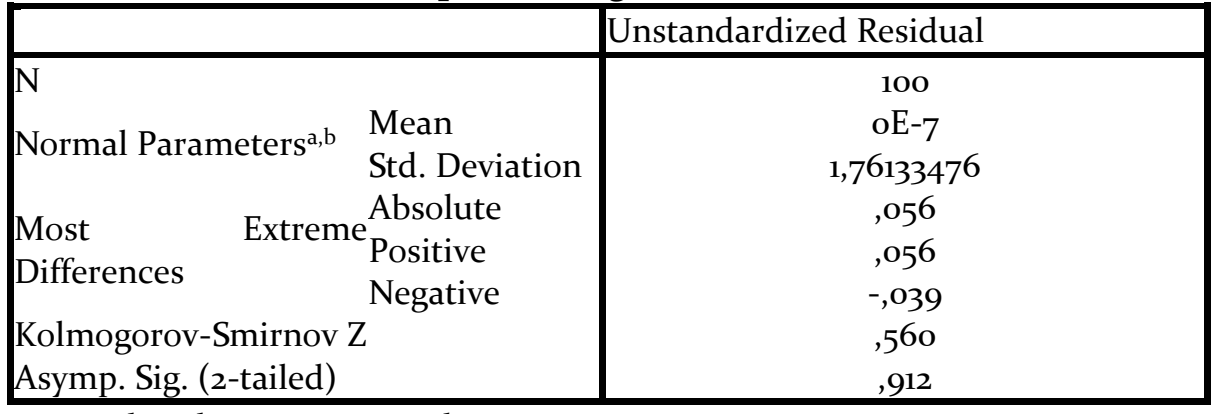

a. Test distribution is Normal.

b. Calculated from data.

Sumber: data primer diolah, 2019

Signifikan $>0,05=$ data terdistribusi normal. Signifikan $<0,05=$ data tidak terdistribusi secara normal

Berdasarkan tabel 3 diatas, hasil pengujian

kolmogorovsmirnov

memperlihatkan nilai asymp-sig (2-tailed) memiliki nilai lebih besar dari 0,05 atau $0,912>0,05$. Hal ini menunjukkan bahwa data terdistribusi secara normal.

\section{Uji Heteroskedastisitas}

Homokedastisitas merupakan hasil model regresi yang baik atau tidak terjadi Heteroskedastisitas. Untuk melihat uji Heteroskedastisitas dapat dilihat dari hasil grafik scatter-plots dimana titik-titik menyebar baik atas atau bawah angka 0 sejajar dengan sumbu Y, dapat disimpulkan bahwa tidak terjadi heteroskedastisitas.

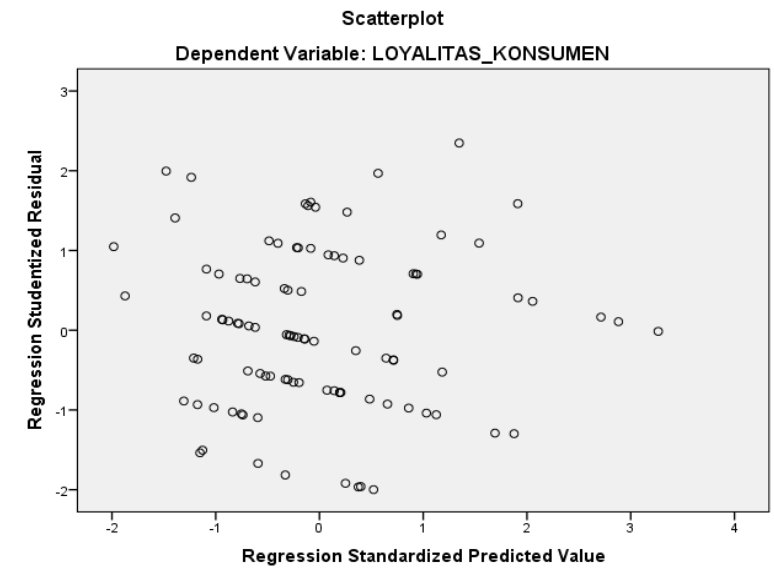

Sumber: data primer diolah, 2019

Gambar 6: Scatterplot Uji Heteroskedastisitas

Dari hasil Gambar 6 diatas tidak terjadi uji heteroskedastisitas karena ada titik-titik yang penyebaran baik atas atau bawah angka 0 sejajar sumbu $\mathrm{Y}$, kesimpulannya tidak terjadi heteroskedastisitas. 


\section{Uji Multikolinearitas}

Hasil uji multikolonieritas dalam penelitian ini terlihat dari hasil tabel:

Tabel 4. Uji Multikolonieritas

\begin{tabular}{|c|c|c|c|c|c|c|c|c|}
\hline \multicolumn{9}{|c|}{ Coefficients ${ }^{a}$} \\
\hline \multirow{2}{*}{\multicolumn{2}{|c|}{ Model }} & \multicolumn{2}{|c|}{$\begin{array}{l}\text { Unstandardized } \\
\text { Coefficients }\end{array}$} & \multirow{2}{*}{$\begin{array}{c}\begin{array}{c}\text { Standardized } \\
\text { Coefficients }\end{array} \\
\text { Beta } \\
\end{array}$} & \multirow[t]{2}{*}{$t$} & \multirow[t]{2}{*}{ Sig. } & \multicolumn{2}{|c|}{$\begin{array}{c}\text { Collinearity } \\
\text { Statistics }\end{array}$} \\
\hline & & $\mathrm{B}$ & Std. Error & & & & Tolerance & VIF \\
\hline \multirow{5}{*}{1} & (Constant) & 13,145 & 959 & & 13,708 & 000 & & \\
\hline & Produk & -.201 & 092 &,- 289 & $-2,197$ & .030 & .555 & 1,802 \\
\hline & Lokasi &,- 039 & 148 &,- 042 &,- 261 & 794 & 369 & 2,711 \\
\hline & Harqa &,- 046 & .084 &,- 074 &,- 544 & .588 & .517 & 1,935 \\
\hline & Promosi & 143 & 094 & 222 & 1,520 & 132 & 451 & 2,215 \\
\hline
\end{tabular}

a. Dependent Variable: Loyalitas Konsumen

Sumber: data primer diolah, 2019

tolerance $<0,1$ atau $\mathrm{VIF}>10=$

atau sampel dengan melalukan uji $\mathrm{F}$

Multikolinearitas

tolerance $>0,1$ atau $\mathrm{VIF}<10=$ Tidak

Multikolinearitas

Hasil tabel diatas dapat dilihat angka tolerance untuk produk 0,555, lokasi 0,369 , harga 0,517 dan promosi 0,451 , sedangkan nilai Variance Inflation Factor (VIF) untuk produk 1,802, lokasi 2,711, harga 1,935 dan promosi 2,215 yang keseluruhan variabel berada di bawah atau tidak lebih dari 10 (tolerance $>0,1$ dan VIF < 10, maka kesimpulannya multikolinearitas tidak terdeteksi antar variabel independent.

\section{Pengujian Hipotesis}

Suatu prosedur dalam pengujian hipotesis dilakukan untuk memutuskan apakah ditolak atau diterima dari hipotesis tentang parameter populasi dan uji t-test (Suhendro, 2016).

a) Ha diterima apabila F-hitung > F-tabel, pada $\alpha=5 \%$ dan nilai $p$-value $<$ level of significant sebesar 0,05.

b) Ha ditolak apabila F-hitung < F-tabel, pada $\alpha=5 \%$ dan nilai $p$-value $>$ level of significant sebesar 0,05.

Pengujian Hipotesis Simultan (Uji F) pada Mini market Indomaret di kota

\section{Pematangsiantar}


Tabel 5. Hasil Pengujian Hipotesis Simultan (Uji F) pada Mini market Indomaret dikota Pematangsiantar

\begin{tabular}{|c|c|c|c|c|c|c|}
\hline & \multicolumn{6}{|c|}{ ANOVA } \\
\hline & Model & $\begin{array}{l}\text { Sum of } \\
\text { Squares }\end{array}$ & df & Mean Square & $\mathbf{F}$ & Sig. \\
\hline \multirow{3}{*}{1} & Regression & 39,508 & 4 & 9.877 & 1,116 & $354^{\circ}$ \\
\hline & Residual & 840,852 & 95 & 8,851 & & \\
\hline & Total & 880,360 & 99 & & & \\
\hline
\end{tabular}

Sumber: data primer diolah, 2019

variabel independent Marketing Mix

Dari tabel 5 Nilai F-hitung adalah 1,116. (Produk Lokasi, Promosi dan Harga) Dengan tingkat signifikansi, $a=5 \%$, df tersebut secara simultan tidak pembilang $=\mathrm{k}-1=5-1=4$, df penyebut berpengaruh signifikansi terhadap $=\mathrm{N}-\mathrm{k}=100-5=95$, df Total $=\mathrm{N}-1=$ variabel dependentt (Loyalitas $100-1=99$ ( $\mathrm{k}=$ =banyak variabel, $\mathrm{N}=$ Konsumen) artinya besar kecilnya banyak sampel). Hasil diperoleh untuk keempat rasio tersebut secara simultan nilai F-tabel sebesar 2,47 maka, $F$-hitung $<$ tidak mempengaruhi Loyalitas konsumen $F$-tabel $(1,116<2,47)$. Oleh karena F-hitung pada mini market Indomaret.

lebih kecil dibandingkan F-tabel, dengan Pengujian Hipotesis Simultan (Uji F) tingkat signifikansi sebesar 0,000 yang pada Mini market Alfamart dikota lebih kecil dari 0,05. Maka $\mathrm{H}_{0}$ diterima, Pematangsiantar

Tabel 6. Hasil Pengujian Hipotesis Simultan (Uji F) pada mini market Alfamaret di Kota Pematangsiantar

\begin{tabular}{|c|c|c|c|c|c|}
\hline \multicolumn{7}{|c|}{ ANOVA $^{\mathrm{a}}$} \\
\hline Model & Sum of Squares & $\mathrm{df}$ & Mean Square & $\mathrm{F}$ & Sig. \\
\hline Regression & 28,582 & 4 & 7,146 & 2,210 &, $074^{\mathrm{b}}$ \\
1 Residual & 307,128 & 95 & 3,233 & & \\
Total & 335,710 & 99 & & & \\
\hline \\
a. Dependent Variable: Loyalitas Konsumen \\
b. Predictors: (Constant), Produk, Lokasi, Promosi, Harqa.
\end{tabular}

Sumber: data primer diolah, 2019

Dari tabel 6 Nilai F-hitung adalah nilai F-tabel sebesar 2.47 maka, F-hitung < 2,210. Dengan tingkat signifikansi, $a=5 \%, \quad F$-tabel $(2,210<2,47)$. Oleh karena $F$-hitung df pembilang $=\mathrm{k}-1=5-1=4$, df penyebut lebih kecil dibandingkan $F_{-t a b e l}$, dengan $=\mathrm{N}-\mathrm{k}=100-5=95$, df Total $=\mathrm{N}-1=$ tingkat signifikansi sebesar 0,000 yang $100-1=99\left(\mathrm{k}=\right.$ banyak variabel, $\mathrm{N}=$ lebih kecil dari 0,05 maka $\mathrm{H}_{0}$ ditolak, ini banyak sampel). Hasil diperoleh untuk berarti bahwa variabel independent 
(Produk, Lokasi, Promosi dan Harga) Pengujian Hipotesis Secara Parsial (Uji tersebut secara simultan tidak t-test)

berpengaruh signifikan terhadap variabel Pengujian Hipotesis Secara Parsial (Uji dependent (Loyalitas Konsumen) artinya keempat rasio tersebut secara simultan meliliki pengaruh terhadap Loyalitas konsumen pada mini market Alfamart.

\section{Uji t-test}

Dilakukan untuk mencari pengaruh masing-masing varibel independent dilakukan dengan pengujian t-test.

\section{t) pada Mini market Indomaret dikota}

\section{Pematangsiantar}

Untuk mengetahui apakah setiap variabel independent (Produk Lokasi, Promosi dan Harga) berpengaruh terhadap variabel dependentt (Loyalitas Konsumen) maka dilakukan pengujian hipotesis secara parsial. Hasil pengolahan data sebagai berikut:

Tabel 7. Hasil Pengujian Hipotesis Parsial (Uji t) pada Mini market Indomaret di Kota Pematangsiantar

\begin{tabular}{|c|c|c|c|c|c|c|}
\hline \multicolumn{7}{|c|}{ Coefficients $^{\mathrm{a}}$} \\
\hline & \multirow{2}{*}{ Model } & \multicolumn{2}{|c|}{$\begin{array}{l}\text { Unstandardize } \\
\text { d Coefficients }\end{array}$} & \multirow{2}{*}{$\begin{array}{c}\text { Standardized } \\
\text { Coefficients } \\
\text { Beta }\end{array}$} & \multirow{2}{*}{$t$} & \multirow{2}{*}{ Sig. } \\
\hline & & $\mathrm{B}$ & $\begin{array}{l}\text { Std. } \\
\text { Error }\end{array}$ & & & \\
\hline \multirow{5}{*}{1} & (Constant) & 11,580 & 2,026 & & 5,715 & .000 \\
\hline & Produk &, 245 &, 126 & 196 & 1,945 & 055 \\
\hline & Lokasi &,- 062 & 143 &,- 044 &,- 435 & 664 \\
\hline & Promosi &,- 013 & 101 &,- 013 &,- 128 & 898 \\
\hline & Harga &,- 094 & 120 &,- 078 &,- 779 & 438 \\
\hline
\end{tabular}

Sumber: data primer diolah, 2019

Dari di atas maka dapat disusun persamaan regresi linear berganda:

$Y=\alpha+\beta_{1} X_{1}+\beta_{2} X_{2}+\beta_{3} X_{3}+\beta_{4} X_{4}+\varepsilon$

$Y=11,580+0,245 X_{1}+-0,062 X_{2}+-0,013 X_{3}+$

$-0,094 X_{4}$

Keterangan :

$\mathrm{Y}=$ Loyalitas konsumen

$\mathrm{X}_{1} \quad=$ Produk

$\mathrm{X}_{2} \quad=$ Lokasi

$\mathrm{X}_{3} \quad=$ Promosi

$\mathrm{X}_{4}=$ Harga

$\alpha \quad=$ Konstanta

$\varepsilon=$ error $\beta_{1}, \beta_{2}, \beta_{3}=$ koefisien regresi yang dan $\beta_{4} \quad$ menunjukkan perubahan variabel dependent berdasarkan pada variabel independent

Regresi linier berganda dapat dilihat nilai konstanta sebesar 11,580, bahwa Loyalitas konsumen mempunyai nilai sebesar 11,580 apabila variabel independent (Produk, Lokasi, Promosi dan Harga) dianggap konstan, namun konstanta menunjukkan hasil yang signifikansi. Besar pengaruh variabel independent terhadap variabel 
dependentt diketahui dari nilai beta unstandardized-coefficient, sedangkan untuk melihat yang paling berpengaruh variabel independent terhadap variabel dependentnya tercermin dalam beta standardized coefficients. independent akan dibandingkan dengan ttabel (dihitung dari two-tailed $\alpha=0,05$ dan derajat kebebasan $(\mathrm{df})=\mathrm{n}-\mathrm{k}-1$, dimana $\mathrm{n}=$ jumlah sampel, $\mathrm{k}=$ jumlah variabel. Hasil olah data, maka secara parsial pengaruh setiap variabel independent terhadap variabel dependentt :

1) Produk nilai t-hitung $=1,945$ dan nilai $\mathrm{t}$-tabel $(0,025 ; 100)=1.984$. Dengan demikian t-hitung $<$ t-tabel yaitu 1,945 $<1.984$ maka Ho diterima, bahwa variabel produk tidak memiliki pengaruh terhadap Loyalitas konsumen pada mini market Indomaret di Kota Pematangsiantar.

2) Lokasi t-hitung $=-0,435$ dan nilai $t$-tabel =1.984. Dengan demikian $\mathrm{t}$-hitung $<\mathrm{t}$-tabel yaitu - 0,435 < 1.984 maka $\mathrm{H}_{0}$ diterima, bahwa variabel lokasi tidak memiliki pengaruh terhadap Loyalitas konsumen
Nilai t-hitung untuk setiap variabel

pada mini market Indomaret di Kota Pematangsiantar.

3) Promosi t-hitung $=-0,128$ dan nilai t-tabel $=1.984$. Dengan demikian $\mathrm{t}$-hitung $<\mathrm{t}$-tabel yaitu $-0,128<1.984$ maka $\mathrm{H}_{0}$ diterima, bahwa variabel promosi tidak memiliki pengaruh terhadap Loyalitas konsumen pada mini market Indomaret di Kota Pematangsiantar.

4) Harga t-hitung $=-0,779$ dan nilai $t$-tabel $=$ 1.984. Dengan demikian $\mathrm{t}$-hitung $<\mathrm{t}$-tabel yaitu $-0,779<1.984$ maka $\mathrm{H}_{0}$ diterima, yang berarti bahwa harga tidak memiliki pengaruh terhadap Loyalitas konsumen pada mini market Indomaret di Kota Pematangsiantar.

Pengujian Hipotesis Secara Parsial (Uji t) pada Mini market Alfamart di Kota

\section{Pematangsiantar}

Tabel 8. Hasil Pengujian Hipotesis Parsial (Uji t) pada Mini market Alfamart di Kota Pematangsiantar 


\begin{tabular}{|c|c|c|c|c|c|c|}
\hline \multicolumn{7}{|c|}{ Coefficients ${ }^{\mathrm{a}}$} \\
\hline & \multirow{2}{*}{ Model } & \multicolumn{2}{|c|}{$\begin{array}{l}\text { Unstandardized } \\
\text { Coefficients }\end{array}$} & \multirow{2}{*}{$\begin{array}{c}\text { Standardized } \\
\text { Coefficients } \\
\text { Beta }\end{array}$} & \multirow{2}{*}{$t$} & \multirow{2}{*}{ Sig. } \\
\hline & & $B$ & $\begin{array}{l}\text { Std. } \\
\text { Error } \\
\end{array}$ & & & \\
\hline \multirow{5}{*}{1} & (Constant) & 13,145 &, 959 & & 13,708 &, 000 \\
\hline & Produk &,- 201 &, 092 &,- 289 & $-2,197$ & .030 \\
\hline & Lokasi &,- 039 & 148 &,- 042 &,- 261 & .794 \\
\hline & Promosi & 143 & 094 &, 222 & 1,520 & 132 \\
\hline & Harga &,- 046 &, 084 &,- 074 &,- 544 &, 588 \\
\hline
\end{tabular}

a. Dependent Variable: Loyalitas Konsumen

Sumber: data primer diolah, 2019

Dari Tabel 8 maka dapat disusun persamaan regresi linear berganda:

$Y=\alpha+\beta_{1} X_{1}+\beta_{2} X_{2}+\beta_{3} X_{3}+\beta_{4} X_{4}+\varepsilon$

$Y=13,145+-0,201 X_{1}+-0,039 X_{2}+-0,143 X_{3}+-$ $0,046 X_{4}$

\section{Keterangan :}

$\begin{array}{lll}\mathrm{Y} & = & \text { Loyalitas konsumen } \\ \mathrm{X}_{1} & = & \text { Produk } \\ \mathrm{X}_{2} & = & \text { Lokasi } \\ \mathrm{X}_{3} & = & \text { Promosi } \\ \mathrm{X}_{4} & = & \text { Harga } \\ \mathrm{A} & = & \text { Konstanta } \\ \mathrm{E} & = & \text { error } \\ \beta_{1}, \beta_{2}, \beta_{3} \text { dan } \beta_{4} & = & \text { koefisien regresi yang } \\ & & \text { menunjukkan perubahan } \\ & & \text { variabel dependent } \\ & & \text { berdasarkan pada } \\ & & \text { variabel independent }\end{array}$

Dari hasil persamaan regresi linier berganda, dapat dilihat nilai konstanta sebesar 13,145, menunjukkan bahwa Loyalitas konsumen mempunyai nilai sebesar 13,145 apabila variabel independent (Produk, Lokasi, Promosi dan Harga) dianggap konstan, namun konstanta menunjukkan hasil yang signifikansi. Untuk mengetahui besar pengaruh variabel independent terhadap variabel dependent terlihat dari beta unstandardized-coefficient, sedangkan untuk melihat yang paling berpengaruh variabel independent terhadap variabel dependentnya tercermin dalam beta standardized-coefficients.

Nilai t-hitung untuk setiap variabel independent akan dibandingkan dengan ttabel (dihitung dari two-tailed $\alpha=0,05$ dan derajat kebebasan $(\mathrm{df})=\mathrm{n}-\mathrm{k}-1$, dimana $\mathrm{n}=$ total sampel, $\mathrm{k}=$ total variabel. Pengolahan data pada tabel 8 diatas, maka secara parsial pengaruh setiap variable independent terhadap variabel dependent:

1. Produk nilai t-hitung $=-2,197$ dan nilai t-tabel $(0,095 ; 100)$ sebesar 1,984. Dengan demikian t-hitung < t-tabel yaitu-2,197 < 1,984. Ho diterima, produk tidak memiliki pengaruh terhadp Loyalitas konsumen pada mini market Alfamart di Kota Pematangsiantar.

2. Lokasi nilai t-hitung sebesar $-0,261$ dan nilai $t$-tabel sebesar 1,984. Dengan demikian t-hitung < t-tabel yaitu - 0,261 < 1,984. $\mathrm{H}_{0}$ diterima, lokasi tidak memiliki pengaruh terhadap Loyalitas 
konsumen mini market Alfamart di Kota Pematangsiantar.

3. Promosi nilai t-hitung $=1,520$ dan nilai $\mathrm{t}$-tabel $=1,984$. Dengan demikian t-hitung $<$ t-tabel yaitu $1,520<1,984$. $\mathrm{H}_{0}$ diterima, promosi tidak memiliki pengaruh terhadap Loyalitas konsumen pada mini market Alfamart di Kota Pematangsiantar.

4. Harga nilai t-hitung $=-0,544$ dan nilai $t-$ tabel $=1,984$. Dengan demikian $\quad \mathrm{t}$-hitung $<$ t-tabel yaitu $-0,544<1,984 . \mathrm{H}_{0}$ diterima, harga memiliki pengaruh terhadap Loyalitas konsumen mini market Alfamart di Kota Pematangsiantar.

\section{SIMPULAN}

Dari hasil uji Asumsi Klasik dan pengujian Hipotesis dapat disimpulkan:

1) Secara parsial, produk tidak memiliki pengaruh terhadap Loyalitas

Konsumen, dimana nilai $\mathrm{t}$-hitung $<\mathrm{t}$-tabel maka $\mathrm{H}_{0}$ diterima, produk tidak memiliki pengaruh terhadap Loyalitas konsumen pada mini market Indomaret di Kota Pematangsiantar. Secara parsial produk tidak memiliki pengaruh terhadap Loyalitas Konsumen, dimana nilai t-hitung $<$ t-tabel maka $\mathrm{H}_{0}$ diterima, produk tidak memiliki pengaruh terhadap Loyalitas konsumen pada mini market Alfamart di Kota Pematangsiantar.

2) Secara parsial, lokasi tidak memiliki pengaruh terhadap Loyalitas konsumen, dimana nilai t-hitung $<\mathrm{t}$-tabel. $\mathrm{H}_{0}$ diterima, yang berarti bahwa lokasi tidak memiliki pengaruh terhadap Loyalitas konsumen pada mini market Indomaret di Kota Pematangsiantar. Pada Alfamart secara parsial menunjukkan bahwa lokasi tidak memiliki pengaruh terhadap Loyalitas konsumen, dimana nilai t-hitung $<\mathrm{t}$-tabel $\mathrm{H}_{0}$ diterima, bahwa lokasi tidak memiliki pengaruh terhadap Loyalitas konsumen pada mini market Alfamart di Kota Pematangsiantar.

3) Secara parsial menunjukkan bahwa promosi tidak memiliki pengaruh terhadap Loyalitas konsumen dimana nilai t-hitung $<\mathrm{t}$-tabel. $\mathrm{H}_{0}$ diterima, bahwa promosi tidak memiliki pengaruh terhadap Loyalitas konsumen pada mini market Indomaret di Kota Pematangsiantar. Pada Alfamart secara parsial menunjukkan bahwa promosi tidak memiliki pengaruh terhadap Loyalitas konsumen dimana nilai t-hitung $<$ t-tabel. $\mathrm{H}_{0}$ diterima, bahwa promosi tidak memiliki pengaruh terhadap Loyalitas konsumen pada mini market Alfamart di Kota Pematangsiantar. 
4) Secara parsial, harga tidak memiliki pengaruh terhadap Loyalitas konsumen dimana nilai t-hitung $<\mathrm{t}$-tabel. $\mathrm{H}_{0}$ diterima, harga tidak memiliki pengaruh terhadap Loyalitas konsumen pada mini market Indomaret di Kota Pematangsiantar. Pada Alfamart secara parsial, harga tidak memiliki pengaruh terhadap Loyalitas konsumen dimana nilai t-hitung $<\mathrm{t}$-tabel. $\mathrm{H}_{0}$ diterima, harga tidak memiliki pengaruh terhadap Loyalitas konsumen pada mini market Alfamart di Kota Pematangsiantar.

5) Secara simultan Marketing Mix (Produk, Lokasi, Promosi dan Harga) tidak memiliki pengaruh signifikansi terhadap variabel dependent (Loyalitas Konsumen) dimana $F$-hitung $<F$-tabel. $\mathrm{H}_{0}$ diterima, variabel independent Marketing Mix (Produk Lokasi, Promosi dan Harga) tersebut secara simultan tidak memiliki pengaruh yang signifikan terhadap variabel dependent (Loyalitas Konsumen) pada Mini market Indomaret di Kota Pematangsiantar sedangkan pada Alfamart secara simultan Marketing Mix (Produk, Lokasi, Promosi dan Harga) tidak memiliki pengaruh signifikan terhadap variable dependent (Loyalitas Konsumen) dimana $F$-hitung $<F$-tabel. $\mathrm{H}_{0}$ diterima, variabel independent Marketing Mix
(Produk, Lokasi, Promosi dan Harga) secara simultan tidak memiliki pengaruh signifikansi terhadap variabel dependent (Loyalitas Konsumen) pada Mini market Alfamart di Kota Pematangsiantar.

\section{DAFTAR PUSTAKA}

BPS Kota Pematangsiantar. (n.d.). Jumlah gerai Indomaret dan Alfamart wilayah Pematangsiantar.

BPS Kota Pematangsiantar. (2017). Jumlah penduduk kota Pematangsiantar berdasarkan kelompok usia dan jenis kelamin.

Danny, T. W., \& Chandra, F. (2001). Analisis Kepuasan dan Loyalitas Konsumen Terhadap Tingkat Penjualan di Warung Bu Kris (Studi Kasus Pada Ayam Penyet Sebagai Menu Unggulan Warung Bu Kris). Jurnal Manajemen Dan Kewirausahaan, 3(2), pp.85-95.

Fahmi, M., \& Yuniati, T. (2013). Pengaruh Kepuasan Dan Loyalitas Pelanggan Honda Terhadap Citra Perusahaan PT AHM. Jurnal Ilmu \& Riset Manajemen, 2(12).

Fuad, A. N., Arifin, Z., \& Yulianto, E. (2013). Pengaruh Bauran Pemasaran Terhadap Keputusan Pembelian (Survei pada Pemilik Sepeda Motor Hornda Beat Karburator di AHASS Barokah Motor Kediri). Jurnal Administrasi Bisnis, 4(1), 1-12.

Guruh Taufan Hariyadi. (2016). Faktor-faktor yang Mempengaruhi Konsumen Berbelanja di Mini market (Studi pada Indomaret dan Alfamart di Semarang). Jurnal Penelitian Ekonomi Dan Bisnis, 1(1), 16-32.

Indomaret. (2018). jumlah Gerai Indomaret.

Kompas. (2018). Jumlah gerai Alfamart.

Marendra, I. G. (2018). Pengaruh Bauran Pemasaran (Produk, Harga, Lokasi Dan Promosi) Terhadap Keputusan Pembelian Konsumen Di Mini market (Alfamart Atau Indomaret). Jurnal Pemasaran Kompetitif, 1(3), 34-52.

Masyhuri, M., \& Utomo, S. W. (2017). Analisis Dampak Keberadaan Pasar Modern terhadap Pasar Tradisional Sleko di Kota MADIUN. Jurnal Akuntansi Dan Pendidikan, Vol. 6 No., 59-72.

Muryuniarsih, Annisa Rahman, dan O. H. (2014). Model Persaingan Bisnis Ritel Mini market di Purwokerto (Studi tentang Persaingan antara 
PT. Indomarco Prismatama dan PT. Sumber Alfaria Trijaya, Tbk). Raushan Fikr, 4(2), 3142.

Mustikawati, I., \& Dody Prihatin Setia Budi, S. S. S. S. K. N. (2012). Analisis Perbandingan Persepsi Konsumen Mini market Indomaret dengan Alfamart di Pasar Jenggawah Kecamatan Jenggawah Kabupaten Jember. Majalah Ilmiah 'DIAN ILMU', 11(2), 1-16.

Putra, A. H., \& Giri, R. R. W. (2013). Analisis Preferensi Konsumen terhadap Mini market di Kota Bandung (Studi Kasus: Alfamart, Indomaret, Yomart, Circle K, Lawson, Yogya Express). Telkom University.

Rizka Nuri Puspita. (2012). Perbedaan Kepuasan Pelanggan Indomaret dan Alfamart. Journal of Sosial and Industrial Psychology, 1(1), 61-67.

Suhendro, D. (2016). Pengaruh Kualitas Sistem, Kualitas Informasi, Kualitas Pelayanan Dan Ekspektasi Kinerja Terhadap Kepuasan Pengguna Dalam Penerapan Sistem Teknologi Informasi Pada Koperasi Di Kota Pematang Siantar. JURASIK, 1(1), 33-40.

T.Teviana, \& Eva Riyanti. (2015). Analisis Perbandingan Persepsi Konsumen Mini market Indomaret dengan Alfamart di Ismaliyah Kecamatan Medan Area Kota Medan. JURNAL PLANS Penelitian LIrnu Manajemen \& Bisnis, X(1), 44-54. 